\title{
Investigation of AlInN HEMT structures with different AlGaN buffer layers grown on sapphire substrates by MOCVD
}

\author{
O. Kelekci ${ }^{\text {a,b, }}$, P. Tasli ${ }^{\text {a,1 }}$, S.S. Cetin ${ }^{\text {a,1 }}$, M. Kasap ${ }^{\text {a,1 }}$, S. Ozcelik ${ }^{\text {a,1 }}$, E. Ozbay ${ }^{\text {b,c,d,2 }}$ \\ ${ }^{a}$ Department of Physics, Faculty of Science and Arts, Gazi University, Teknikokullar, 06500 Ankara, Turkey \\ ${ }^{\mathrm{b}}$ Nanotechnology Research Center, Bilkent University, Bilkent, 06800 Ankara, Turkey \\ ${ }^{\mathrm{c}}$ Department of Physics, Bilkent University, Bilkent, 06800 Ankara, Turkey \\ ${ }^{\mathrm{d}}$ Department of Electrical and Electronics Engineering, Bilkent University, Bilkent, 06800 Ankara, Turkey
}

\section{A R T I C L E I N F O}

\section{Article history:}

Received 29 January 2012

Received in revised form

14 April 2012

Accepted 14 May 2012

Available online 1 June 2012

\section{Keywords:}

Nitride materials

Electrical transport

Electronic band structure

\begin{abstract}
A B S T R A C T
We investigate the structural and electrical properties of $\mathrm{Al}_{x} \mathrm{In}_{1-\gamma} \mathrm{N} / \mathrm{AlN} / \mathrm{GaN}$ heterostructures with AlGaN buffers grown by MOCVD, which can be used as an alternative to AlInN HEMT structures with GaN buffer. The effects of the GaN channel thickness and the addition of a content graded AlGaN layer to the structural and electrical characteristics were studied through variable temperature Hall effect measurements, high resolution XRD, and AFM measurements. Enhancement in electron mobility was observed in two of the suggested $\mathrm{Al}_{x} \mathrm{In}_{1-x} \mathrm{~N} / \mathrm{AlN} / \mathrm{GaN} / \mathrm{Al}_{0.04} \mathrm{Ga}_{0.96} \mathrm{~N}$ heterostructures when compared to the standard $\mathrm{Al}_{x} \mathrm{In}_{1-x} \mathrm{~N} / \mathrm{AlN} / \mathrm{GaN}$ heterostructure. This improvement was attributed to better electron confinement in the channel due to electric field arising from piezoelectric polarization charge at the $\mathrm{Al}_{0.04} \mathrm{Ga}_{0.96} \mathrm{~N} / \mathrm{GaN}$ heterointerface and by the conduction band discontinuity formed at the same interface. If the growth conditions and design parameters of the $\mathrm{Al}_{x} \mathrm{In}_{1-\gamma} \mathrm{N}$ HEMT structures with AlGaN buffers can be modified further, the electron spillover from the GaN channel can be significantly limited and even higher electron mobilities, which result in lower two-dimensional sheet resistances, would be possible.
\end{abstract}

(c) 2012 Elsevier B.V. All rights reserved.

\section{Introduction}

$\mathrm{Al}(\mathrm{In}) \mathrm{GaN} /(\mathrm{In}) \mathrm{GaN}$-based high-electron mobility transistors (HEMTs) have been studied extensively as ideal candidates for high frequency and high power applications [1,2]. In order to improve the performance of devices, various barrier and channel alternatives have been used in nitride based HEMTs [3-9]. Several achievements have been made in AlGaN/GaN HEMT performance by optimizing the material quality, device fabrication, and the epitaxial layer designs [10]. An AlN interlayer has been inserted between the AlGaN barrier and GaN layer, which makes polarization effects stronger and this causes a higher sheet carrier

\footnotetext{
* Corresponding author. Department of Physics, Faculty of Science and Arts, Gazi University, Teknikokullar, 06500 Ankara, Turkey. Tel.: +90312 2903050; fax: +903122901015 .

E-mail addresses: okelekci@bilkent.edu.tr (O. Kelekci), pttasli@gmail.com (P. Tasli), cetins@gazi.edu.tr (S.S. Cetin), mkasap@gazi.edu.tr (M. Kasap), sozcelik@ gazi.edu.tr (S. Ozcelik), ozbay@bilkent.edu.tr (E. Ozbay).

1 Fax: +90312 2122279

2 Fax: +90312 2901015 .
}

density. In addition, due to less alloy disorder scattering, a higher mobility has been achieved [3-6]. Moreover, achieving higher 2DEG densities in either undoped or modulation-doped AIGaN HEMT structures requires the growth of ternary alloys with higher $\mathrm{Al}$ composition in which the polarization-induced electric field is much larger. However, growing AlGaN layers with a high $(>\% 30)$ Al mole fraction contains problems due to the large tensile strain that these layers experience. This tensile strain degrades the quality of the layer above a critical thickness and then causes a significant reduction in electron mobility [6,11]. To overcome this problem, Kuzmík proposed using a nearly latticematched AlInN/GaN structure to improve the performance of HEMTs with high sheet carrier densities provided by spontaneous polarization only $[12,13]$. Following the original proposal of Kuzmik, AlInN barriers have become increasingly attractive due to their much higher spontaneous polarization, which leads to higher 2DEG densities even with zero piezoelectric polarization and allows thinner barrier thicknesses compared to AlGaN $[14,15]$. In addition, as AlInN barriers can be grown latticematched to GaN, they have the potential to reduce the density of strain-related defects. 
Table 1

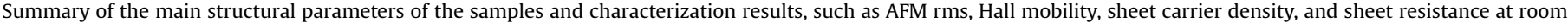
temperature.

\begin{tabular}{|c|c|c|c|c|c|c|}
\hline Sample & Buffer & $\begin{array}{l}\text { GaN channel } \\
\text { thickness (nm) }\end{array}$ & $\begin{array}{l}\text { rms roughness } \\
(\mathrm{nm})\end{array}$ & $\begin{array}{l}\text { Mobility } \\
@ 300 \\
\text { K }\left(\mathrm{cm}^{2} / \text { V.s }\right)\end{array}$ & $\begin{array}{l}\text { 2DEG density } \\
@ 300 \mathrm{~K}\left(\times 10^{13} \mathrm{~cm}^{-2}\right)\end{array}$ & $\begin{array}{l}\text { Sheet resistance } \\
@ 300 \mathrm{~K}(\Omega / \mathrm{sq})\end{array}$ \\
\hline A (control) & GaN & - & 0.54 & 841 & 2.54 & 292 \\
\hline B & $\mathrm{Al}_{0.04} \mathrm{Ga}_{0.96} \mathrm{~N}$ & 20 & 0.58 & 918 & 2.02 & 337 \\
\hline C & $\mathrm{Al}_{0.04} \mathrm{Ga}_{0.96} \mathrm{~N}$ & 40 & 0.51 & 1013 & 1.97 & 313 \\
\hline D & $\begin{array}{l}\mathrm{Al}_{0.04} \mathrm{Ga}_{0.96} \mathrm{~N} \\
+ \text { Graded } \mathrm{Al}_{x} \mathrm{Ga}_{1-\chi} \mathrm{N}\end{array}$ & 20 & 0.70 & 723 & 1.91 & 453 \\
\hline
\end{tabular}

Table 2

The material parameters used for the energy band profile and sheet carrier density calculations. [31]

\begin{tabular}{lccc}
\hline Parameter & AlN & GaN & InN \\
\hline$a(\AA)$ & 3.112 & 3.189 & 3.545 \\
$e_{31}\left(\mathrm{C} / \mathrm{m}^{2}\right)$ & -0.50 & -0.35 & -0.57 \\
$e_{33}\left(\mathrm{C} / \mathrm{m}^{2}\right)$ & 1.79 & 1.27 & 0.97 \\
$C_{13}(\mathrm{GPa})$ & 108 & 106 & 92 \\
$C_{33}(\mathrm{GPa})$ & 373 & 398 & 224 \\
$P_{\mathrm{SP}}\left(\mathrm{C} / \mathrm{m}^{2}\right)$ & -0.081 & -0.029 & -0.032 \\
\hline
\end{tabular}

Recent advances in the growth of AlInN have resulted in respectable HFET performance in devices employing this lattice matched barrier [16-23]. Gonschorek et al. improved the mobility to $1170 \mathrm{~cm}^{2} / \mathrm{V}$ for an undoped nearly lattice-matched AlInN/GaN heterostructure, but the low temperature mobility was still low when compared to the AlGaN/GaN HEMT structures [24]. They inserted an AlN interlayer between the AlInN and GaN layers to suppress alloy-disorder scattering, which has also been demonstrated in AlGaN/GaN heterostructures. Hiroki et al. employed AlInN/AlGaN double barriers in order to make the surface flatter and they obtained a mobility of $1960 \mathrm{~cm}^{2} / \mathrm{V}$ but with the cost of a significant reduction in sheet carrier density $\left(9 \times 10^{12} \mathrm{~cm}^{-2}\right)[22]$. In addition to these efforts, $\mathrm{Wu}$ et al. have grown nearly latticematched AlInN HEMT structures on Fe-doped semi-insulating GaN substrates in order to obtain high power levels owing to the good thermal conductivity of GaN substrates [18]. Despite these works reported in the literature, alternative buffers for AlInN HEMT structures have not been studied systematically, which is very important for obtaining high-electron mobilities and low leakage currents.

In this study, we aim to investigate the potential use of AlGaN buffers in AllnN HEMT structures, which were also used in AlGaN/ GaN heterostructures in order to improve electron confinement in the channel [25-29]. Electrical and structural characteristics of AlInN HEMT structures with different AlGaN buffers and with a
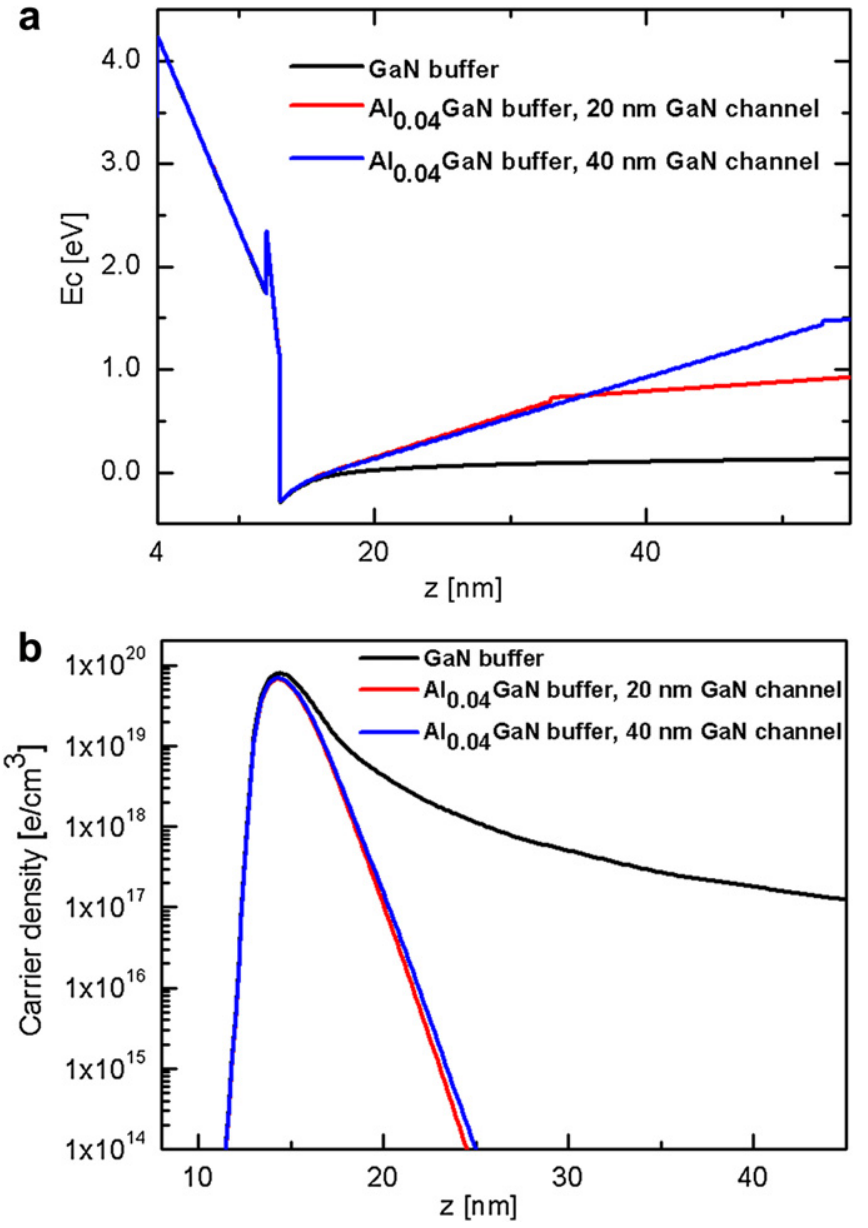

Fig. 2. (a) Calculated conduction band profiles and (b) The carrier distributions along the $z$ axis for the AlInN heterostructure with standard GaN buffer and the structure with AlGaN buffers.

\begin{tabular}{|l|}
\hline GaN cap $\sim 2 \mathrm{~nm}$ \\
\hline $\mathrm{Al}_{\mathrm{x}} \mathrm{In}_{1-\mathrm{x}} \mathrm{N} \sim 8 \mathrm{~nm}$ \\
\hline $\mathrm{AIN} \sim 1 \mathrm{~nm}$ \\
\hline $\mathrm{GaN}$ buffer $\sim 2 \mu \mathrm{m}$ \\
\hline $\mathrm{HT}$ AIN layer $\sim 0.4 \mu \mathrm{m}$ \\
\hline $\mathrm{AIN}$ nucleation layer $15 \mathrm{~nm}$ \\
\hline $\mathrm{Al}_{2} \mathrm{O}_{3}$ substrate \\
\hline Sample-A
\end{tabular}

Sample-A

\begin{tabular}{|l|}
\hline GaN cap $\sim 2 \mathrm{~nm}$ \\
\hline $\mathrm{Al}_{x} \mathrm{In}_{1-\mathrm{x}} \mathrm{N} \sim 8 \mathrm{~nm}$ \\
\hline $\mathrm{AIN} \sim 1 \mathrm{~nm}$ \\
\hline $\mathrm{GaN}$ channel $\sim 20 \mathrm{~nm}, 40 \mathrm{~nm}$ \\
\hline $\mathrm{Al}_{0.04} \mathrm{Ga}_{0.96} \mathrm{~N}$ buffer $\sim 1.1 \mu \mathrm{m}$ \\
\hline $\mathrm{HT}$ AIN layer $\sim 0.4 \mu \mathrm{m}$ \\
\hline $\mathrm{AlN}_{\mathrm{N}}$ ncleation layer $\sim 15 \mathrm{~nm}$ \\
\hline $\mathrm{Al}_{2} \mathrm{O}_{3}$ substrate \\
\hline
\end{tabular}

Sample-B , Sample-C

\begin{tabular}{|c|}
\hline GaN cap $\sim 2 \mathrm{~nm}$ \\
\hline $\mathrm{Al}_{\mathrm{x}} \mathrm{In}{ }_{1-\mathrm{x}} \mathrm{N} \sim 8 \mathrm{~nm}$ \\
\hline AIN $\sim 1 \mathrm{~nm}$ \\
\hline GaN channel $\sim 20 \mathrm{~nm}$ \\
\hline $\mathrm{Al}_{0.04} \mathrm{Ga}_{0.96} \mathrm{~N}$ buffer $\sim 1.1 \mu \mathrm{m}$ \\
\hline $\mathrm{Al}_{x} \mathrm{Ga}_{1-x} \mathrm{~N} \mathrm{x}=1$ to $0.04, \sim 450 \mathrm{~nm}$ \\
\hline HT AIN layer $\sim 0.4 \mu \mathrm{m}$ \\
\hline AIN nucleation layer $\sim 15 \mathrm{~nm}$ \\
\hline $\mathrm{Al}_{2} \mathrm{O}_{3}$ substrate \\
\hline
\end{tabular}

Fig. 1. Schematic cross-sectional view of the investigated AlInN HEMT structures. 
standard GaN buffer were compared. Electrical characterization of the samples is performed by using variable temperature Hall effect measurements in a temperature range of $30-300 \mathrm{~K}$, and structural characteristics were obtained through AFM and high resolution XRD measurements.

\section{Experimental details}

$\mathrm{Al}_{0.82} \mathrm{In}_{0.18} \mathrm{~N} / \mathrm{AlN} / \mathrm{GaN} / \mathrm{Al}_{0.04} \mathrm{Ga}_{0.96} \mathrm{~N}$ HEMT structures were grown on 2 inch c-plane (0001) sapphire substrates in a vertical low-pressure metal-organic chemical vapor deposition (Aixtron 200/4 RF-S) system. Prior to epitaxial growth, the sapphire substrate was annealed at $1050{ }^{\circ} \mathrm{C}$ for $10 \mathrm{~min}$ in order to remove surface contamination. The growth was initiated with a $15 \mathrm{~nm}$ thick low temperature (LT) AlN nucleation layer at a temperature of $770{ }^{\circ} \mathrm{C}$. Then, a $400 \mathrm{~nm}$ high temperature (HT) AlN layer was grown at a temperature of $1125{ }^{\circ} \mathrm{C}$. A $1.1 \mu \mathrm{m}$ thick nominally undoped $\mathrm{Al}_{0.04} \mathrm{Ga}_{0.96} \mathrm{~N}$ buffer layer (BL) was then grown at $1030{ }^{\circ} \mathrm{C}$ and a reactor pressure of 140 mbar. After the $\mathrm{Al}_{0.04} \mathrm{Ga}_{0.96} \mathrm{~N}$ BL, GaN channel layers were grown at the same temperature. The growth time was adjusted in order to obtain GaN channel layers with the desired thickness. In order to reduce the alloy disorder scattering, a $\sim 1 \mathrm{~nm}$ thick HT AlN inter layer was grown at a temperature of $1075{ }^{\circ} \mathrm{C}$. An $8 \mathrm{~nm} \mathrm{Al} \mathrm{Al}_{0.82} \mathrm{In}_{0.18} \mathrm{~N}$ barrier layer was deposited on the AlN inter layer at a growth temperature of $830{ }^{\circ} \mathrm{C}$. The growths were finalized by growing a $2 \mathrm{~nm}$ thick GaN cap layer at $830^{\circ} \mathrm{C}$. In Sample-D, a $450 \mathrm{~nm}$ graded $\mathrm{Al}_{x} \mathrm{Ga}_{1-x} \mathrm{~N}$ layer $\left(x=x_{1} \rightarrow x_{2}\right)$ was deposited by linearly lowering the Al composition $x$ from $x_{1}=100 \%$ to $x_{2}=4 \%$ toward the upper side on the high temperature AIN buffer layer at a temperature range of $1125^{\circ} \mathrm{C}-1030^{\circ} \mathrm{C}$. As a reference, one sample was grown without AlGaN buffer but with a $2 \mu \mathrm{m}$ GaN buffer layer. All the layers were nominally undoped. After growth, the samples were characterized by high resolution X-ray diffraction (HR-XRD), atomic force microscopy (AFM), and variable temperature Hall measurements. The details of all the samples are shown in Table 1.

For the Hall effect measurements, square shaped samples in Van der Pauw geometry were prepared with four evaporated Ti/Al/Ni/ Au triangular ohmic contacts at the corners. The ohmic behavior of the contacts was confirmed by the current-voltage $(I-V)$ characteristics. The measurements were performed at a constant magnetic field of $0.4 \mathrm{~T}$ and at various temperatures over a temperature range of $30-300 \mathrm{~K}$ by using a Lake Shore Hall effect measurement system.
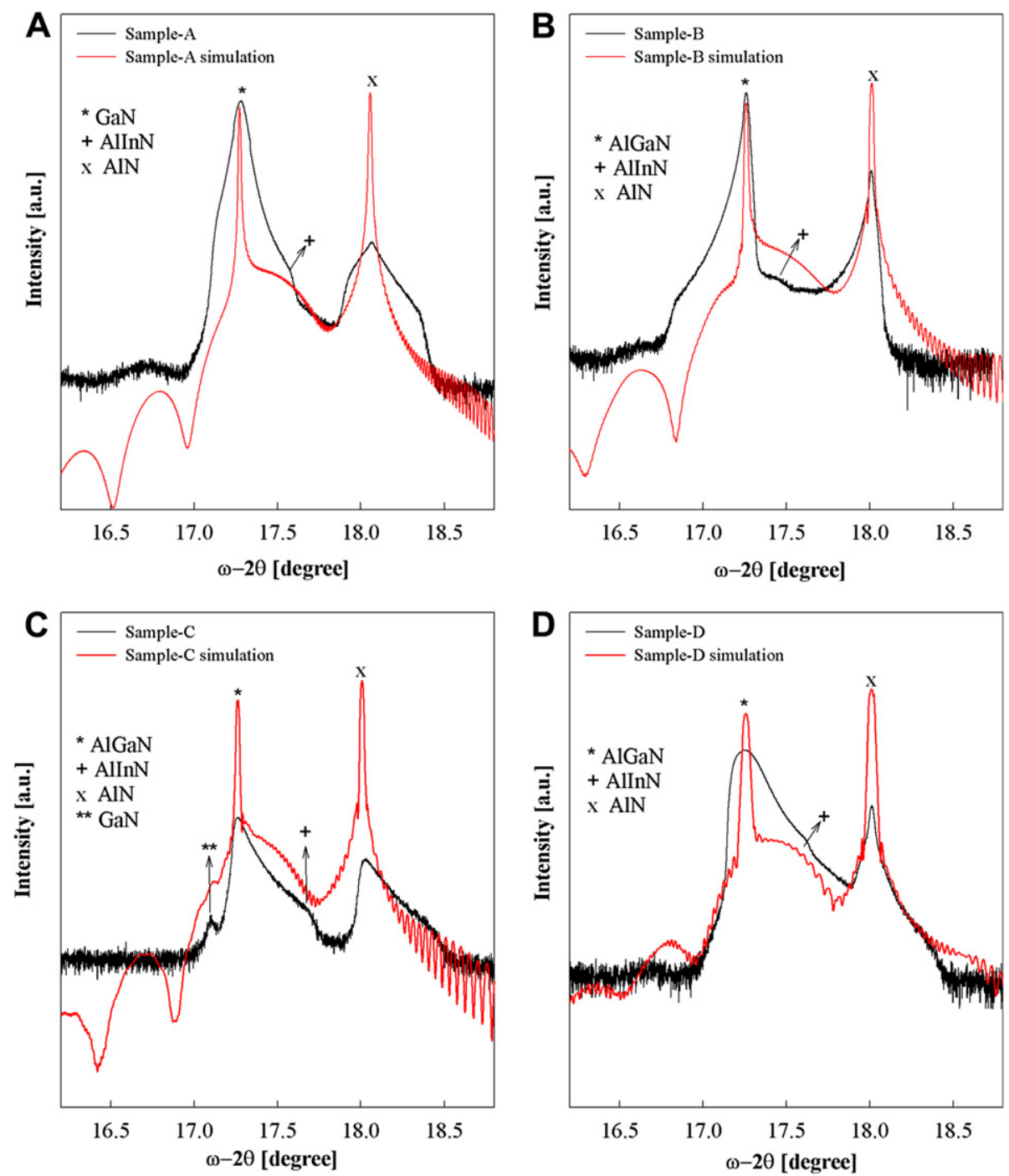

Fig. 3. HR-XRD (0002) $\omega-2 \theta$ scans of $\mathrm{Al}_{x} \mathrm{In}_{1-x} \mathrm{~N} / \mathrm{AlN} / \mathrm{GaN}$ heterostructures with AlGaN buffers and standard GaN buffer along with the simulation curves (samples $\mathrm{A}-\mathrm{D}$ ). 


\section{Results and discussion}

The conduction band profile and carrier distribution for the AlInN/AlN/GaN and AlInN/AlN/GaN/AlGaN structures is calculated by solving one-dimensional non-linear Schrödinger-Poisson equations, self-consistently including polarization-induced carriers [30]. The material parameters used for the calculations were taken from [31] and tabulated in Table 2. The cross-sectional schematic diagram of the investigated AlInN HEMT structures is shown in Fig. 1. The conduction band profiles and carrier distributions of the AlInN HEMTs are shown in Fig. 2. It is clearly seen in Fig. 2 that the AlGaN buffers would significantly improve the electron confinement in the channel. The electron confinement in the AlInN/AIN/GaN/AlGaN heterostructure is improved by the electric field arising from the piezoelectric polarization charge at the $\mathrm{Al}_{0.04} \mathrm{Ga}_{0.96} \mathrm{~N} / \mathrm{GaN}$ heterointerface and by the conduction band discontinuity at the same interface [25-28]. Since the AlGaN alloy within an $\mathrm{Al}$ content of $10-90 \%$ has high thermal resistance [32], the Al composition of thick AlGaN buffers were kept around $4 \%$ for the AlInN/AlN/GaN/AlGaN samples. In order to observe the effect of GaN channel thickness, $20 \mathrm{~nm}$ and $40 \mathrm{~nm}$ thick GaN channels were grown in sample-B and sample-C, respectively. Moreover, a $450 \mathrm{~nm}$ thick composition graded $\mathrm{Al}_{x} \mathrm{Ga}_{1-x} \mathrm{~N}$ layer was grown before the $\mathrm{Al}_{0.04} \mathrm{Ga}_{0.96} \mathrm{~N}$ buffer in sample-D, which was expected to provide a better transition from the HT AIN layer to the $\mathrm{Al}_{0.04} \mathrm{Ga}_{0.96} \mathrm{~N}$ buffer layer.
High resolution $\mathrm{x}$-ray diffraction (HR-XRD) measurements were performed to determine the overall structural quality and the alloy compositions of four samples. X-ray data were collected on the (0002) reflections with $\omega-2 \theta$ scans. Fig. 3 shows $\omega-2 \theta$ scan HRXRD patterns around the (0002) reflection for $\mathrm{Al}_{\mathrm{x}} \mathrm{In}_{1-\mathrm{x}} \mathrm{N} / \mathrm{AlN} / \mathrm{GaN}$ heterostructures with AlGaN buffers and standard GaN buffer along with the simulation curves. The simulations of HR-XRD scan data were performed with the commercial software LEPTOS 4.02 by using kinetic and dynamic methods. The two main peaks are the (0002) zeroth-order Bragg reflections from the GaN BL (sample-A)/ $\mathrm{Al}_{0.04} \mathrm{Ga}_{0.96} \mathrm{~N}$ BL (sample-B, C, D) and AlN layer. Indium compositions of the AlInN barrier layers were determined as $19.5 \%, 20 \%$, and $21 \%$ for samples A, B, C-D, respectively. The Indium composition variation in the samples can be explained by the composition pulling effect due to the different misfit strains in the films [27]. Due to the nearby strong peak of thick GaN/AlGaN layers it is not possible to get a strong signal from thin AlInN ( $x \sim 18-20 \%)$ barrier layers in XRD measurements. The actual Indium composition can be somewhat debatable but such small variation in Indium content of AlInN barrier layers would not violate the arguments made on the electrical properties of the studied samples.

The full width at half maximum (FWHM) values, determined from the X-ray rocking curves for the symmetric plane (0002) of AlGaN(GaN)/AlN layers in samples A, B, C, and D, are obtained as $256 / 634,165 / 183,187 / 190$, and 666/136 arcsec, respectively. As the FWHM values of AlGaN layers in samples B, C, and D are compared, it
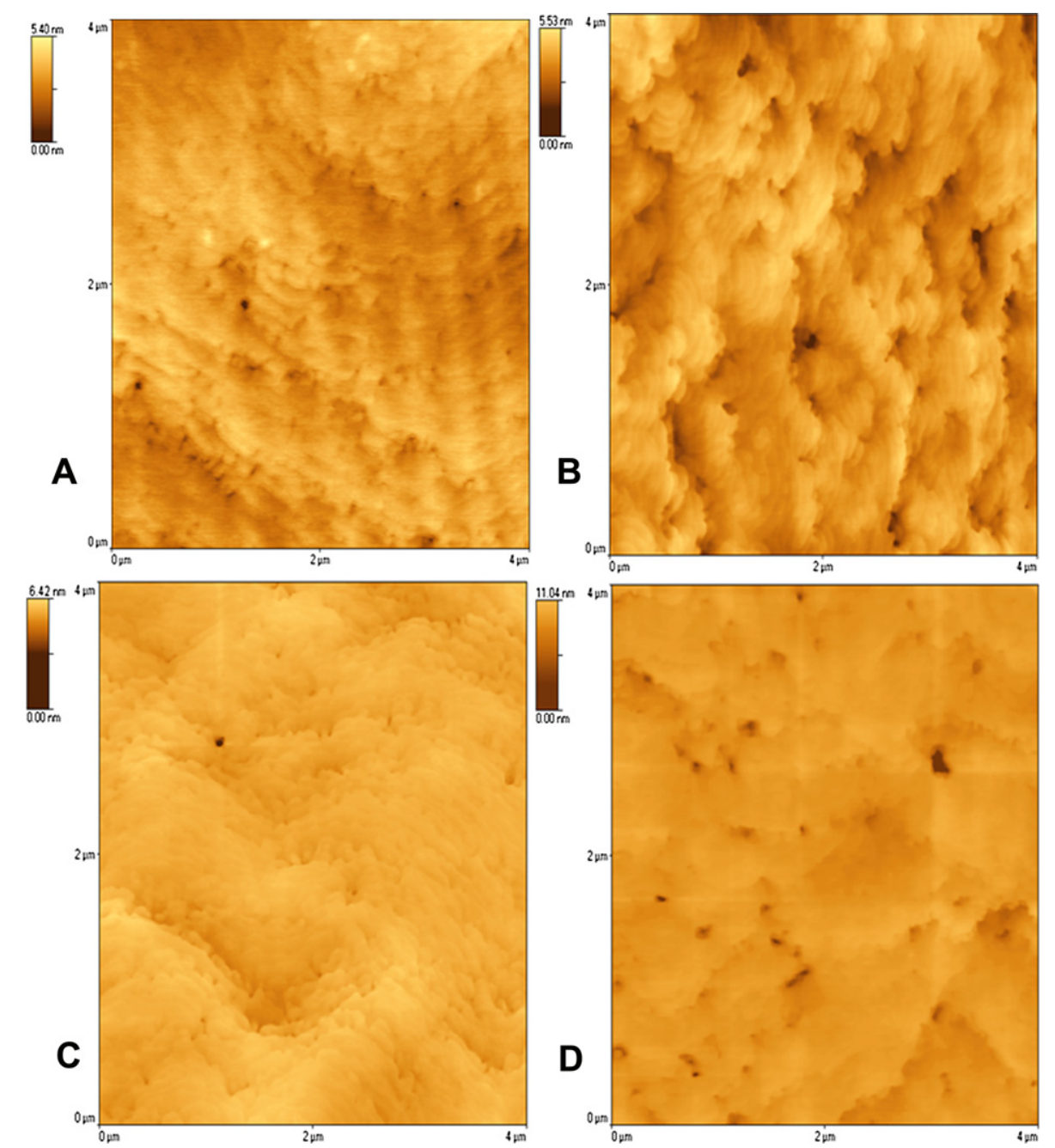

Fig. 4. $4 \times 4 \mu \mathrm{m}^{2}$ AFM images of the samples (A-D). The rms roughness values are $0.54 \mathrm{~nm}, 0.58 \mathrm{~nm}, 0.51 \mathrm{~nm}$, and $0.70 \mathrm{~nm}$ for the samples A, B, C, and D, respectively. 

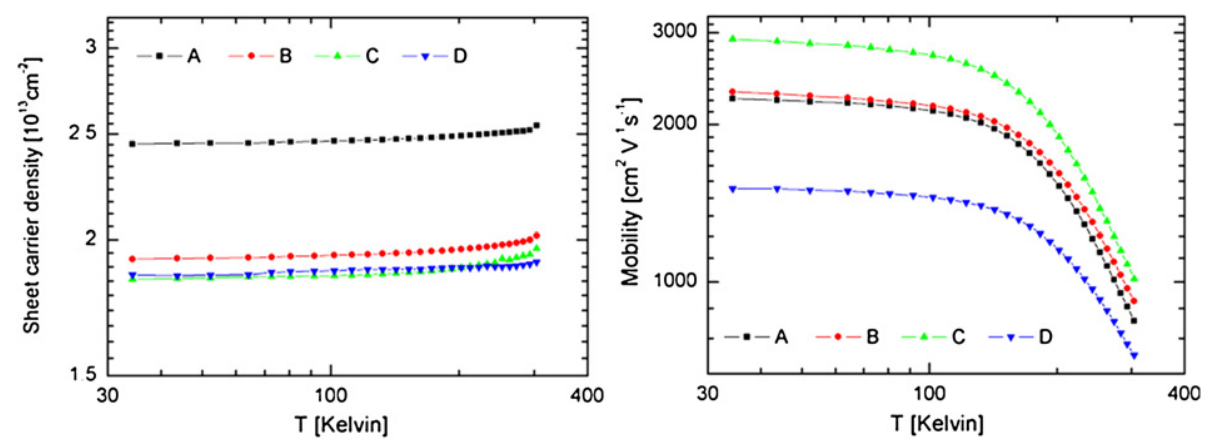

Fig. 5. Temperature dependence of measured mobility and sheet carrier density for all of the grown samples.

is clearly seen that the insertion of graded AlGaN layer leads to a more broadened peak. In addition, the peak of GaN channel layer becomes more distinguishable from the peak of AlGaN buffer layer for sample C, which has a thicker GaN channel than that of sample-B.

Fig. 4 shows AFM images with a $4 \times 4 \mu \mathrm{m}^{2}$ scan area obtained from the GaN cap layer surfaces of samples A, B, C, and D. The surfaces of the samples mainly consist of steps and terraces. The measured rms surface roughnesses are $0.54 \mathrm{~nm}, 0.58 \mathrm{~nm}, 0.51 \mathrm{~nm}$, and $0.70 \mathrm{~nm}$ for the samples A, B, C, and D, respectively. The rms values demonstrate that the samples have smooth surfaces and are in agreement with the terrace widths on the GaN surfaces. The relatively high rms roughness of sample-D is probably due to the presence of large pits and narrow steps on its surface. These roughness values are generally consistent with mobility values because of interface roughness scattering. However, interface roughness is not the only reason for low mobility.

Hall measurements of the grown samples as a function of the temperature (30-300 K) were performed at a constant magnetic field $(0.4 \mathrm{~T})$. Fig. 5 shows the temperature-dependent Hall sheet carrier density and mobility data for all of the AlInN HEMT structures. As seen in the figure, the sheet carrier densities for all the samples remain nearly constant through the studied temperature range. This temperature behavior of sheet carrier densities implies that the conduction is dominated almost exclusively by the carriers at the AlN/GaN heterointerfaces. Measured mobility values of samples B and C are higher than that of sample-A (control sample) in the whole temperature range, while Sample-D has the lowest mobility among all the samples. The observed mobility enhancement in these samples can be attributed to the piezoelectrically enhanced electron confinement and the large conduction band discontinuity formed at the $\mathrm{Al}_{0.04} \mathrm{Ga}_{0.96} \mathrm{~N} / \mathrm{GaN}$ heterointerface. The electron confinement could increase the screening effect against the ionized impurity scattering and dislocations that plays an important role in determining the 2DEG mobility [33,34]. On the other hand, mobility enhancement, which is obtained in sample-B (20 nm thick GaN channel), is not as significant as in sample-C (40 nm thick GaN channel). Compared to the sample-C, the lower 2DEG mobility obtained in the sample- $B$ might be due to the inferior crystalline quality of the thin GaN channel. The threading dislocations coming from the underlying layers can probably be threaded all the way through the thin GaN channel. This situation is also confirmed by the AFM surface roughness measurements. Moreover, the observation of the lowest mobility $\left(723 \mathrm{~cm}^{2} \mathrm{~V}^{-1} \mathrm{~s}^{-1}\right)$ in sample-D can also be explained by degraded crystal quality. In addition, a low mobility three-dimensional channel originating from the graded AlGaN layer could be formed in parallel with the main 2-D channel [35]. Small differences in Indium compositions of the AlInN barrier layers (revealed by XRD analyses) might have effect on the mobility of the samples. However, the effect caused by this small difference of barrier composition is not expected to be significant when compared with the effects caused by the buffer and channel parameters [36]. When 2DEG densities of the samples are compared, sample-A (control sample) has the highest 2DEG density $\left(2.54 \times 10^{13} \mathrm{~cm}^{-2}\right)$, which is consistent with the calculations. The depletion due to negative polarization charges at the $\mathrm{Al}_{0.04} \mathrm{Ga}_{0.96} \mathrm{~N}$ buffer/GaN channel interface significantly decreases the sheet carrier density in the AlInN heterostructures with AlGaN buffers.

It is apparent that the major difference in the total sheet carrier density of AlInN/AlN/GaN/AlGaN structures and standard AlInN/ AlN/GaN structures comes from the electrons spread over the GaN buffer. These electrons will contribute little to peak current, but may be responsible for the buffer leakage in possible transistor applications. Therefore, employing $\mathrm{Al}_{\mathrm{x}} \mathrm{Ga}_{1-\mathrm{x}} \mathrm{N}$ buffers in AlInN HEMTs and optimizing the layers properly might further limit the electron spillover from the GaN channel and suppress the buffer leakage of the HEMT devices. However, device application is beyond the scope of the present paper.

\section{Conclusion}

We have studied the structural and electrical properties of $\mathrm{Al}_{x} \mathrm{In}_{1-x} \mathrm{~N} / \mathrm{AlN} / \mathrm{GaN}$ heterostructures with AlGaN buffers grown by MOCVD, which can be used as an alternative to AlInN HEMT structures with GaN buffer. The effects of the GaN channel thickness and the addition of a content graded AlGaN layer to the structural and electrical characteristics were investigated. In addition, the composition pulling effect was observed in the AlInN barriers due to the different misfit strains in the films. Enhancement in electron mobility was observed in two of the suggested AlInN HEMT structures with AlGaN buffers when compared to the structure with GaN buffer. This mobility enhancement was attributed to better electron confinement in the channel due to the electric field arising from the piezoelectric polarization charge at the $\mathrm{Al}_{0.04} \mathrm{Ga}_{0.96} \mathrm{~N} / \mathrm{GaN}$ heterointerface and by the conduction band discontinuity formed at the same interface. Although our study shows that there is the potential of performance enhancement in AlInN HEMT structures with AlGaN buffers further studies are needed to fully evaluate and exploit the promise of these heterostructures with AlGaN buffers.

\section{Acknowledgments}

This work is supported by the State Planning Organization of Turkey under Grant No. 2001K120590, by the European Union under the projects PHOME, ECONAM, N4E, and TUBITAK under Project Nos. 109E301, 107A004, 107A012, and DPT under the project DPT-HAMIT. One of the authors (E.O.) also acknowledges partial support from the Turkish Academy of Sciences. 


\section{References}

[1] M.S. Shur, Solid State Electron 42 (1998) 2131.

[2] H. Morkoç, Handbook of Nitride Semiconductors and Devices, vol. 3, WileyVCH Verlag GmbH, 2009.

[3] L. Shen, S. Heikman, B. Moran, R. Coffie, N.Q. Zhang, D. Buttari, I.P. Smorchkova, S. Keller, S.P.DenBaars, U.K. Mishra, IEEE Electr. Device Lett. 22(2001) 457.

[4] C.M. Wang, X.L. Wang, G.X. Hu, J.X. Wang, J.P. Li, Z.G. Wang, Appl. Surf. Sci. 253 (2006) 762

[5] R.S. Balmer, K.P. Hilton, K.J. Nash, M.J. Uren, D.J. Wallis, A. Wells, M. Missous, T. Martin, Phys. Stat. Sol.(c) 0 (2003) 2331.

[6] I.P. Smorchkova, L. Chen, T. Mates, L. Shen, S. Heikman, B. Moran, S. Keller, S.P. DenBaars, J.S. Speck, U.K. Mishra, J. Appl. Phys. 90 (2001) 5196.

[7] I.P. Smorchkova, S. Keller, S. Heikman, C.R. Elsass, B. Heying, P. Fini, J.S. Speck, U.K. Mishra, Appl. Phys. Lett. 77 (2000) 3998.

[8] G. Simin, A. Koudymov, H. Fatima, J. Zhang, J. Yang, M.A. Khan, X. Hu, A. Tarakji, R. Gaska, M.S. Shur, IEEE Elec. Dev. Lett. 23 (2002) 458.

[9] J.X. Ran, X.L. Wang, G.X. Hu, W. Luo, Z. Ma, J.P. Li, C. Wang, J. Wang, Y. Zeng, J. Li, X. Liu, J. Liu, Z. He, Proc. 8th Int. Conf. on Solid-State and Integrated Circuit Technology Part 2, IEEE, Shanghai, China, 2006, 929-931.

[10] U.K. Mishra, L. Shen, T.E. Kazior, Y.-F. Wu, Proc. IEEE 96 (2008) 287.

[11] S. Arulkumaran, T. Egawa, H. Ishikawa, T. Jimbo, J. Vac. Sci. Technol. B 21 (2003) 888 .

[12] J. Kuzmík, IEEE Electron Device Lett. 22 (2001) 510.

[13] J. Kuzmík, Semicond. Sci. Technol. 17 (2002) 540.

[14] R. Tülek, A. Ilgaz, S. Gökden, A. Teke, M.K. Öztürk, M. Kasap, S. Özçelik, E. Arslan, E. Özbay, J. Appl. Phys. 105 (2009) 013707.

[15] A. Teke, S. Gökden, R. Tülek, J.H. Leach, Q. Fan, J. Xie, Ü. Özgür, H. Morkoç, S.B. Lisesivdin, E. Özbay, New J. Phys. 11 (2009) 063031.

[16] F. Medjdoub, M. Alomari, J.-F. Carlin, M. Gonschorek, E. Feltin, M.A. Py, N. Grandjean, E. Kohn, IEEE Electron Device Lett. 29 (2008) 422

[17] J.W. Chung, O.I. Saadat, J.M. Tirado, X. Gao, S. Guo, T. Palacios, IEEE Electron Device Lett. 30 (2009) 904.

[18] M. Wu, J.H. Leach, X. Ni, X. Li, J. Xie, S. Dogan, Ü. Özgür, H. Morkoç, T. Paskova, E. Preble, K.R. Evans, C.Z. Lu, J. Vac. Sci. Technol. B 28 (2010) 908.
[19] M. Alomari, F. Medjdoub, J.-F. Carlin, E. Feltin, N. Grandjean, A. Chuvilin, U. Kaiser, C. Gaquière, E. Kohn, IEEE Electron Device Lett. 30 (2009) 1131.

[20] H. Sun, A.R. Alt, H. Benedickter, E. Feltin, J.-F. Carlin, M. Gonschorek, N. Grandjean, C.R. Bolognesi, IEEE Electron Device Lett. 31 (2010) 957.

[21] S. Guo, X. Gao, D. Gorka, J.W. Chung, H. Wang, T. Palacios, A. Crespo, J.K. Gillespie, K. Chabak, M. Trejo, V. Miller, M. Bellot, G. Via, M. Kossler, H. Smith, D. Tomich, Phys. Status Solidi A 207 (2010) 1348.

[22] M. Hiroki, N. Maeda, T. Kobayashi, Phys. Status Solidi C 6 (2009) S1056

[23] H. Yu, M. Ozturk, P. Demirel, H. Cakmak, B. Bolukbas, D. Caliskan, E. Ozbay, Semicond. Sci. Technol. 26 (2011) 085010.

[24] M. Gonschorek, J.-F. Carlin, E. Feltin, M.A. Py, N. Grandjean, Appl. Phys. Lett. 89 (2006) 062106

[25] N. Maeda, T. Saitoh, K. Tsubaki, T. Nishida, N. Kobayashi, Jpn. J. Appl. Phys. 38 (1999) L799.

[26] C.Q. Chen, J.P. Zhang, V. Adivarahan, A. Koudymov, H. Fatima, G. Simin, J. Yang, M.A. Khan, Appl. Phys. Lett. 82 (2003) 4593.

[27] Z. Chen, Y. Pei, S. Newman, D. Brown, R. Chung, S. Keller, S.P. DenBaars, S. Nakamura, U.K. Mishra, Appl. Phys. Lett. 94 (2009) 171117.

[28] H. Yu, S.B. Lisesivdin, B. Bolukbas, O. Kelekci, M.K. Ozturk, S. Ozcelik, D. Caliskan, M. Ozturk, H. Cakmak, P. Demirel, E. Ozbay, Phys. Status Solidi A 207 (2010) 2593.

[29] E. Bahat-Treidel, O. Hilt, F. Brunner, J. Würfl, G. Tränkle, Phys. Status Solidi C 6 (2009) 1373.

[30] S. Birner, S. Hackenbuchner, M. Sabathil, G. Zandler, J.A. Majewski, T. Andlauer, T. Zibold, R. Morschl, A. Trellakis, P. Vogl, Acta Phys. Pol. A 110 (2006) 111.

[31] I. Vurgaftman, J.R. Meyer, L.R. Ram-Mohan, J. Appl. Phys. 89 (2001) 5815.

[32] W.L. Liu, A.A. Balandin, J. Appl. Phys. 97 (2005) 073710.

[33] N.G. Weimann, L.F. Eastman, D. Doppalapudi, H.M. Ng, T.D. Maustakus, J. Appl. Phys. 83 (1998) 3656.

[34] T. Ando, A.B. Fowler, F. Stern, Rev. Mod. Phys. 54 (1982) 437.

[35] S. Rajan, S.P. DenBaars, U. Mishra, H. Xing, D. Yena, Appl. Phys. Lett. 88 (2006) 042103.

[36] M. Azize, T. Palacios, J. Appl. Phys. 108 (2010) 023707. 